\title{
Phylogeography of the red coral (Corallium rubrum): inferences on the evolutionary history of a temperate gorgonian
}

\author{
D. Aurelle $\cdot$ J.-B. Ledoux $\cdot$ C. Rocher . \\ P. Borsa $\cdot$ A. Chenuil $\cdot$ J.-P. Féral
}

\begin{abstract}
The red coral Corallium rubrum (Cnidaria, Octocorallia) is an exploited, long-lived sessile species from the Mediterranean Sea and the adjacent coastline in the Atlantic Ocean. Surveys of genetic variation using microsatellites have shown that populations of $C$. rubrum are characterized by strong differentiation at the local scale but a study of the phylogeography of this species was still lacking. Here, we used seven polymorphic microsatellite loci, together with sequence data from an intron of the elongation factor 1 (EF1) gene, to investigate the genetic structure of $C$. rubrum across its geographical range in the western Mediterranean Sea and in the Adriatic Sea. The EF1 sequences were also used to analyse the consequences of demographic fluctuations linked with past environmental change. Clustering analysis with microsatellite loci highlighted three to seven genetic groups with the distinction of North African and Adriatic populations; this distinction appeared significant with AMOVA and differentiation tests. Microsatellite and EF1 data extended the
\end{abstract}

D. Aurelle $(\bowtie) \cdot$ J.-B. Ledoux $\cdot$ C. Rocher $\cdot$ A. Chenuil · J.-P. Féral

CNRS UMR 6540 DIMAR, Centre d'Océanologie de Marseille, Aix-Marseille Université, Station Marine d'Endoume, rue de la batterie des Lions, 13007 Marseille, France

e-mail: didier.aurelle@univmed.fr

\section{J.-B. Ledoux}

Institut de Ciències del Mar CSIC, Passeig Maritim de la Barceloneta 37-49, 08003 Barcelona, Spain

P. Borsa

Institut de recherche pour le développement, UR 227,

Montpellier, France isolation by distance pattern previously observed for this species at the western Mediterranean scale. EF1 sequences confirmed the genetic differentiation observed between most samples with microsatellites. A statistical parsimony network of EF1 haplotypes provided no evidence of high sequence divergence among regions, suggesting no longterm isolation. Selective neutrality tests on microsatellites and EF1 were not significant but should be interpreted with caution in the case of EF1 because of the low sample sizes for this locus. Our results suggest that recent Quaternary environmental fluctuations had a limited impact on the genetic structure of $C$. rubrum.

Keywords Red coral · Phylogeography · Genetic structure $\cdot$ EPIC $\cdot$ Microsatellites

\section{Introduction}

The phylogeographic approach yields insights into the evolutionary history of a species by revealing vicariance events, migration pathways and population expansion or bottleneck (Avise 2000). Phylogeography also assists the management of threatened species by providing information on genetic subdivisions, gene flow and genetic diversity. This is crucial in the present context of global change (including climate change) where species dynamics is linked to dispersal and recolonisation abilities, and to the possibility of in situ adaptation. Despite the need of genetic data for adequate management strategies, such data are still scarce in most marine species (Féral 2002). Until recently, this was also the case for the red coral, Corallium rubrum, in the Mediterranean Sea.

C. rubrum is a sessile cnidarian inhabiting caves, vertical cliffs and overhangs at depths ranging from $10 \mathrm{~m}$ to more 
than $800 \mathrm{~m}$ (Garrabou and Harmelin 2002; Costantini et al. 2010). It has a fragmented pattern of distribution and occurs in the western Mediterranean, in some parts of the eastern Mediterranean and on the neighbouring Atlantic coasts such as those of Morocco (Zibrowius et al. 1984). C. rubrum has long been exploited for jewellery. $C$. rubrum has also been affected by mortality events linked with positive thermal anomalies in 1999 and 2003 (Garrabou et al. 2009) which may have impacted the population dynamics of this species (Santangelo et al. 2007). C. rubrum is a sessile species with relatively short larval phase (4-12 days in aquaria; Vighi 1972; Weinberg 1979) and therefore, presumably low dispersal abilities. C. rubrum is an appropriate model to study the genetic consequences of past and current environmental fluctuations. Genetic consequences of Quaternary climatic fluctuations have been studied for terrestrial species (Hewitt 2000; Petit et al. 2003) but less frequently in the marine realm. Concerning the Mediterranean Sea, at the last glacial maximum (LGM) 20,000 years ago, the sea level in the north western Mediterranean Sea was around 105-115 m below the present level (Lambeck and Bard 2000). Few sessile species (necessarily more strongly affected by recent fluctuations than mobile ones) have been analysed from the point of view of the genetic consequences of sea-level variations in the Mediterranean Sea (but see Duran et al. 2004; Serra et al. 2010). Two different scenarios can be proposed for the evolutionary history of red coral shallow-water populations in this context. The "refugia" scenario postulates that red coral populations would have established through long distance colonisation events from putative distant refugia within the last 20,000 years: the localization of these putative refugia and the possibility of long-distance migration events remain to be investigated. In the North Atlantic similar scenarios with different refugia (not only southern but also periglacial refugia) have been inferred from genetic data for benthic species (Maggs et al. 2008). In the "persistence" scenario, the shallow-water populations would have originated from ancestral populations whose habitat gradually expanded upwards. A similar hypothesis has been proposed by Marko et al. (2010) in the north eastern Pacific. These opposite scenarios are expected to leave different genetic signatures (Hewitt 2000; Marko et al. 2010) but intermediate hypotheses should be considered as well. Analysing past demographic changes and population connectivity may also provide valuable insights into the potential future evolution of populations in a context of global change (Maggs et al. 2008).

Previous genetic studies of $C$. rubrum have been performed with allozymes (Abbiati et al. 1993), AFLP (del Gaudio et al. 2005) and microsatellites (Costantini and Abbiati 2006; Costantini et al. 2007a, b, 2010; Ledoux et al. 2010a, b). These studies indicated generalised genetic differentiation among populations, even at short distances (starting around $10 \mathrm{~m}$ ) and therefore, low effective dispersal. No major genetic break was observed among the most distant populations and a regional pattern of isolation by distance was evidenced by Ledoux et al. (2010a) along with local spatial genetic structure between individuals (Ledoux et al. 2010b).

So far no study was specifically dedicated to the evolutionary history of red coral and nucleotide sequence data were still needed to evaluate divergence times and to analyse past demographic fluctuations. Mitochondrial DNA is not variable enough in this species (Calderón et al. 2006). Internal transcribed spacers (ITS) were used as nuclear sequence markers in red coral by Costantini et al. (2007b, 2010), but they have shown high levels of intra-individual variability in another octocoral species, Eunicella cavolinii (Calderón et al. 2006). Here we present an evaluation of ITS intra-individual variability along with new data from an exon priming intron crossing (EPIC) marker from the elongation factor 1 (EF1) gene in C. rubrum. Nuclear sequence markers (including another part of EF1) have already shown much higher variability than mitochondrial DNA in cnidarians and have been used to reveal population isolation in Oculina sp. (Eytan et al. 2009). We assess the variability of this new marker and use it for the study of the phylogeography of $C$. rubrum.

The present study includes samples of C. rubrum from the south western Mediterranean and the North Adriatic regions in addition to samples formerly studied with microsatellites by Ledoux et al. (2010a). Our objective is to investigate the phylogeography of the red coral across a larger part of its geographical range and to identify the main genetic subdivisions over this area. We extended the microsatellite data of Ledoux et al. (2010a) and analysed EF1 sequence data in order to assess the levels of divergence between populations and to look for potential signals of past demographic fluctuations.

\section{Materials and methods}

\section{Samples}

The samples and their geographical distribution are presented in Table 1 and Fig. 1. Sampling was hierarchical and included nine regions: the Adriatic Sea, North Africa, Corsica, South Italy (Ionian Sea), North Italy (Ligurian Sea), Balearic Islands, Marseilles, Monaco (Ligurian Sea) and Catalonia, with several localities in most cases, resulting in 39 samples. Regions were delineated according to microsatellite results (Ledoux et al. 2010a; our results) and to geographical breaks (e.g. island vs. mainland). The sampling protocol is described in Ledoux et al. (2010a).

For intron sequences we tried as far as possible to obtain samples scattered throughout the corresponding 
Table 1 Corallium rubrum samples: location, hydrographic region, identification code, depth, sample size for microsatellites, sample size for $\mathrm{EF} 1$, and observed heterozygosity (Hobs) for EF1

\begin{tabular}{|c|c|c|c|c|c|c|}
\hline Regions, Sampling site & $\begin{array}{l}\text { Hydrographic } \\
\text { region }\end{array}$ & Code & Depth (m) & $\begin{array}{l}\text { Sample size } \\
\text { microsatellites } \\
\text { (individuals) }\end{array}$ & $\begin{array}{l}\text { Sample size EF1 } \\
\text { (individuals) }\end{array}$ & Hobs EF1 \\
\hline \multicolumn{7}{|l|}{ Adriatic Sea } \\
\hline Sazan, Albania & Adriatic Sea & ALB & 58 & 20 & 14 & 0.50 \\
\hline Garmenjak Veli Islet, Croatia & Adriatic Sea & GHA & 57 & 30 & 7 & 0.29 \\
\hline Total Adriatic Sea & & & & $\mathbf{5 0}$ & 21 & \\
\hline \multicolumn{7}{|l|}{ North Africa } \\
\hline Tenes & SW Mediterranean & TEN & 47 & 15 & 5 & 0.80 \\
\hline Tenes & SW Mediterranean & TNS & $33-36$ & 15 & $\mathbf{0}$ & \\
\hline Ciclon de Fuera & Alboran Sea & FUE & $25-30$ & 22 & 18 & 0.72 \\
\hline Cueva del Coral & Alboran Sea & DEL & 42 & 15 & 9 & 0.44 \\
\hline Total North Africa & & & & 67 & 32 & \\
\hline \multicolumn{7}{|l|}{ Corsica } \\
\hline Baja Casju & NW Mediterranean & $\mathrm{BCA}$ & 30 & 28 & 1 & 0 \\
\hline Cala di Ponte & NW Mediterranean & CDP & $26-27$ & & 2 & 0 \\
\hline Palazzinu (cave) & NW Mediterranean & PUA & 40 & & 1 & 0 \\
\hline Palazzu & NW Mediterranean & PZU & 22 & 34 & 7 & 0.29 \\
\hline Palazzu deep & NW Mediterranean & PZP & 40 & & 9 & 0 \\
\hline Porto & NW Mediterranean & POR & 24 & 30 & 4 & 0 \\
\hline Total Corsica & & & & 92 & 24 & \\
\hline \multicolumn{7}{|l|}{ South Italy } \\
\hline Apulia & Ionian Sea & APU & 45 & & 7 & 0.57 \\
\hline Total South Italy & & & & & 7 & \\
\hline \multicolumn{7}{|l|}{ North Italy } \\
\hline Portofino & Ligurian Sea & PDA & 35 & 30 & 7 & 0.43 \\
\hline Total North Italy & & & & & 7 & \\
\hline \multicolumn{7}{|l|}{ Balearic Islands } \\
\hline Cap Formentor & Balearic Sea & FOR & $36-38$ & 32 & 4 & 0.25 \\
\hline Llosa des Patro Pere & Balearic Sea & LPP & $34-36$ & 30 & 8 & 0.25 \\
\hline Total Balearic Islands & & & & 62 & 12 & \\
\hline \multicolumn{7}{|l|}{ Marseilles } \\
\hline Carro & Gulf of Lion & $\mathrm{CRO}$ & 21 & 35 & 3 & 0.33 \\
\hline Carry le Rouet & Gulf of Lion & CAR & 20 & 37 & 3 & 0 \\
\hline Figuier (cave) & Gulf of Lion & FII & 20 & & 1 & 0 \\
\hline Grand Congloué & Gulf of Lion & GC & 40 & & 1 & 1 \\
\hline Grotte à Peres (inside cave) & Gulf of Lion & GPI & 20 & & 3 & 1 \\
\hline Grotte à Peres (outside cave) & Gulf of Lion & GPE & 20 & & 2 & 0 \\
\hline Impériales du Large & Gulf of Lion & IML & 60 & & 5 & 0.40 \\
\hline Plane & Gulf of Lion & PLA & $38-41$ & & 1 & 0 \\
\hline Ponteau & Gulf of Lion & PON & 21 & 28 & 4 & 0 \\
\hline Riou (inside cave) & Gulf of Lion & RII & 20 & 36 & 14 & 0.14 \\
\hline Riou (outside cave) & Gulf of Lion & RIE & 20 & 30 & 8 & 1 \\
\hline Riou deep (outside cave) & Gulf of Lion & RIO & 40 & & 1 & 1 \\
\hline Tiboulen du Frioul & Gulf of Lion & TFR & $38-40$ & 42 & 1 & 0 \\
\hline Tremies (cave) & Gulf of Lion & TRM & $14-15$ & & 1 & 0 \\
\hline Total Marseilles & & & & 208 & 48 & \\
\hline
\end{tabular}


Table 1 continued

\begin{tabular}{|c|c|c|c|c|c|c|}
\hline Regions, Sampling site & $\begin{array}{l}\text { Hydrographic } \\
\text { region }\end{array}$ & Code & Depth (m) & $\begin{array}{l}\text { Sample size } \\
\text { microsatellites } \\
\text { (individuals) }\end{array}$ & $\begin{array}{l}\text { Sample size EF1 } \\
\text { (individuals) }\end{array}$ & Hobs EF1 \\
\hline \multicolumn{7}{|l|}{ Côte d'Azur } \\
\hline Monaco & Ligurian Sea & MON & $35-38$ & 23 & 7 & 0.43 \\
\hline Villefranche sur Mer & Ligurian Sea & VIL & $22-24$ & 36 & 2 & 0 \\
\hline Total Villefranche-Monaco & & & & 59 & 9 & \\
\hline \multicolumn{7}{|l|}{ Catalonia } \\
\hline Cap de Norfeu & NW Mediterranean & NOR & 24 & 31 & 8 & 0 \\
\hline Cova de la Reina & NW Mediterranean & CDR & $14-17$ & 38 & 3 & 0.33 \\
\hline Cova de la Vaca & NW Mediterranean & $\mathrm{COV}$ & 18 & & 1 & 0 \\
\hline Meda Xica & NW Mediterranean & XIC & 35 & & 2 & 0.50 \\
\hline Pota del Lop & NW Mediterranean & POT & 35 & 35 & 8 & 0.63 \\
\hline Cap de l'Abeille & NW Mediterranean & BAN & 25 & & 1 & 1 \\
\hline Sec Rederis & NW Mediterranean & SRE & $23-24$ & 27 & 5 & 0.60 \\
\hline Total Catalonia & & & & 131 & 28 & \\
\hline
\end{tabular}

For microsatellites, sample sizes in bold correspond to samples analysed for this paper; other sample sizes correspond to data from Ledoux et al. (2010a). EF1 data have all been obtained for the current article

geographical regions. Concerning microsatellites, 18 samples already analysed by Ledoux et al. (2010a) were considered here along with six new samples: four from North Africa (TEN, TNS, FUE, DEL) and two from the Adriatic Sea (ALB, GHA; Table 1). Because the intra-regional genetic structure was not the aim of this paper, a maximum of six samples per region were analysed in order to avoid any over-representation of some regions (Marseilles for example) in the dataset.

Evaluation of intra-individual variability for internal transcribed spacers

We evaluated the intra-individual variability of ITS1. The corresponding methods and results are presented and

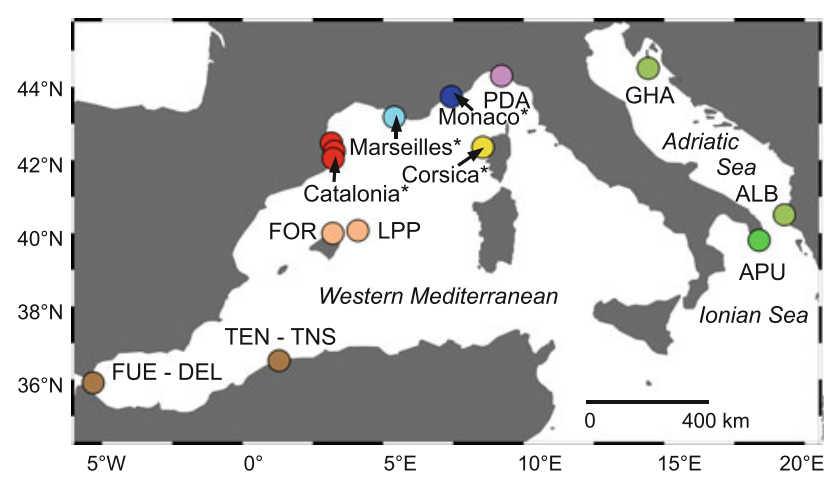

Fig. 1 Map of sampling localities of Corallium rubrum. Population codes are presented in Table 1. FUE and DEL samples are about $2 \mathrm{~km}$ apart; TEN and TNS correspond to two samples from the same site but at different depths (Table 1). Asterisks indicate regions covering several sampling sites, detailed in Table 1; the precise locations of populations inside these regions are described in Ledoux et al. (2010a) discussed in supplementary material. We evidenced a high level of intra-individual variability for ITS1. Considering this variability we did not use this locus for further analyses and instead focused our sequencing effort on EF1.

Molecular analyses of EF1

\section{Total DNA extraction}

Genomic DNA was extracted using the QIAmp DNA Mini Kit $50\left(\right.$ Qiagen $\left.^{\circledR}\right)$, following manufacturer's instructions, or with phenol—chloroform protocol (Ledoux et al. 2010a). In both cases extractions were performed from 5 to 15 polyps per colony or, when not possible, using coenenchyme scraped from the colony.

\section{EF1 sequencing}

EF1 cDNA isolation and sequencing are described in supplementary material. The cDNA EF1 sequence was used to define primers with the online Primer 3 software (Rozen and Skaletsky 2000) in order to amplify overlapping fragments of 200-300 bp of the cDNA. These primers were applied to genomic DNA to identify introns. We considered that an intron was identified when the amplified fragment using the genomic DNA template was longer than the corresponding cDNA fragment. One primer pair (EF1 CR4 F: TAGA TAGCATTCTTCCTCCCAAAC and EF1 CR4 R: AACC AACATTATCTCCAGGAAGAG) gave regular amplification of an intron and its flanking regions. PCR conditions for this EF1 EPIC marker were: Promega ${ }^{\circledR}$ PCR buffer 1X, $\mathrm{MgCl}_{2} 2.5 \mathrm{mM}$, dNTPs $0.125 \mathrm{mM}, 0.5 \mu \mathrm{M}$ of each primer, 
Flexigotaq polymerase (Promega ${ }^{\circledR}$ ) $0.025 \mathrm{U}_{\mu}{ }^{-1}$, and $5 \mu \mathrm{l}$ of DNA for a $50 \mu \mathrm{l}$ reaction volume. The PCR program was: 3 min at $94^{\circ} \mathrm{C}, 35$ cycles with $\left[1 \mathrm{~min}\right.$ at $94^{\circ} \mathrm{C}, 1 \mathrm{~min}$ at $59^{\circ} \mathrm{C}$, $1 \mathrm{~min}$ at $72^{\circ} \mathrm{C}$ ], and a final extension of $5 \mathrm{~min}$ at $72^{\circ} \mathrm{C}$. PCR products were sent to the Genomer sequencing platform (Roscoff, France) or to the Genome Express ${ }^{\circledR}$ company for purification and sequencing.

EF1 sequences are available in Genbank under accession numbers GQ202326 to GQ202528.

Microsatellites analysis and polymorphism

The samples analysed with microsatellites are described in Table 1. Seven loci (Mic13, 20, 24, 26, 27, COR9bis and COR46bis) were analysed following Ledoux et al. (2010a). The three other loci used by Ledoux et al. (2010a), Mic 22, 23 and 25, were not used here because they did not give any amplification in the Adriatic and North African samples. The parameters describing the levels of polymorphism (number of alleles by locus $\mathrm{N}_{\mathrm{a}}$, unbiased expected heterozygosity $\mathrm{H}_{\mathrm{nb}}$, and observed heterozygosity $\mathrm{H}_{\mathrm{obs}}$ ) have been computed with the Genetix 4.05.2 software (Belkhir et al. 1996). The departure from panmixia has been evaluated with the $f$ estimator of $F_{I S}$ (Weir and Cockerham 1984); we tested for its significance with 1,000 permutations with Genetix.

EF1 sequence data and polymorphism

Sequences were aligned with BioEdit 7.0.5.3 (Hall 1999). For EF1 intron, individuals with ambiguous sites were considered as heterozygous. For individuals heterozygous at only one site, we directly inferred the two corresponding haplotypes. As some ambiguous/heterozygous positions were observed for various EF1 sequences, we tested whether this was due to heterozygous individuals by cloning the PCR product for twelve individuals: this confirmed that these individuals were indeed heterozygous and this allowed us to identify the corresponding haplotypes. Apart from the cloned PCR products, the haplotypes of the other heterozygous individuals were determined with the Phase 2.1 software (Stephens et al. 2001; Stephens and Scheet 2005). The homozygous individuals and the heterozygous individuals for which the corresponding haplotypes had been identified were used as known phases resulting in 142 reference individuals. Five independent runs were performed with the multi-allelic option without stepwise mutation and other parameters set as defaults. Phase also allowed estimation of the recombination parameter $\rho$ (Li and Stephens 2003). We did not get readable sequences for some individuals heterozygous for insertion-deletion (indels), and they were not used for further analyses (Table 1).
Observed heterozygosities for EF1 were calculated with the number of observed heterozygous individuals based on observed sequence ambiguities and cloning of PCR products. Nucleotide diversity $(\pi)$ and gene diversity (Nei 1987) were calculated with DNAsp 5.0 (Librado and Rozas 2009) at the population and at the regional level according to the geographical groups indicated in Table 1.

Tests of mutation-drift equilibrium

We tested the null hypothesis of mutation-drift equilibrium for microsatellite loci with the Bottleneck 1.2 software (Cornuet and Luikart 1996). We performed the one tail Wilcoxon's tests for heterozygosity excess or deficiency which could indicate a recent bottleneck or population expansion, respectively. The tests were based on 1,000 replications with a two-phase mutation model with $95 \%$ single-step mutations and 5\% multiple-step mutations and a variance among multiple steps of 12 , as recommended by Piry et al. (1999).

DNAsp was used to test for mutation-drift equilibrium with EF1 sequence data with a comparison of three different tests. Fu's Fs test (Fu 1997) and the R2 test (Ramos-Onsins and Rozas 2002) are among the most powerful selective neutrality tests when there is no recombination (RamírezSoriano et al. 2008; Ramos-Onsins and Rozas 2002). When recombination is suspected, Ramírez-Soriano et al. (2008) advise the use of R2 and Tajima's D (Tajima 1989) test. Significance was assessed with coalescent simulations based on the observed theta per gene value with no recombination (according to Phase results) or intermediate levels of recombination (with $R=10$ per gene and 494 sites). One thousand replicates were used for each analysis. As the power of neutrality tests may be greatly reduced for low sample sizes (Ramos-Onsins and Rozas 2002), they were also performed by grouping samples at the regional and global (all samples) levels. The interpretation of the results took into account the different properties of local, scattered and pooled samples in these tests (Städler et al. 2009).

Network reconstruction

EF1 sequences were used for a network reconstruction with the statistical parsimony approach implemented in TCS 1.21 (Clement et al. 2000) with a 95\% limit to parsimony and indels considered as a fifth state.

\section{Clustering analysis}

Microsatellite loci were used for a Bayesian clustering analysis with the Structure 2.2 software (Pritchard et al. 2000) from $K=1$ to 25 groups with five replicates for each run. An admixture model with correlated allele 
frequencies was chosen (Falush et al. 2003) with the option of inferring alpha. Another analysis was also performed with independent allele frequencies and five replicates to check the stability of the results to the chosen model. Preliminary tests showed that a burnin of 50,000 iterations was enough to get a stationary evolution for the likelihood. For each run, this burn-in was followed by 200,000 iterations. The estimation of the number $\mathrm{K}$ of genetic groups was performed by considering the peaks in the second order rate of change of the likelihood function with respect to $\mathrm{K}$ (Delta(K); Evanno et al. 2005) and by focusing on values of $\mathrm{K}$ that capture most of the structure in the data (Pritchard et al. 2007).

Principal coordinate analysis

Genetic relationships among populations were studied with a Principal Coordinate Analyses (PCA) performed with the Genalex 6 software (Peakall and Smouse 2006) on microsatellite data. The analysis used the algorithm of Orloci (1978) with the option of standardized distances and was based on $\mathrm{F}_{\mathrm{ST}}$ values.

\section{Population differentiation and AMOVA}

The analysis of population differentiation was performed with the Arlequin 3.0 software (Excoffier et al. 2005). Pairwise comparisons with microsatellites were analysed with the $\theta$ estimator of $\mathrm{F}_{\mathrm{ST}}$ (Weir and Cockerham 1984). For EF1, pairwise comparisons were done using $\mathrm{F}_{\mathrm{ST}}$ and with $\Phi_{\mathrm{ST}}$ computed with proportion of differences between haplotypes (Excoffier et al. 1992). Both $\mathrm{F}_{\mathrm{ST}}$ and $\Phi_{\mathrm{ST}}$ were tested with 1,000 permutations.

An analysis of molecular variance (AMOVA; Excoffier et al. 1992) was performed on EF1 and microsatellites with Arlequin 3.0 in order to evaluate genetic differentiation within groups and between groups of populations. Nine population groups were defined according to their geographical origin leading to the following groups: Adriatic Sea, North Italy (one population), South Italy (one population; not analysed with microsatellites), Monaco, Marseilles, Catalonia, Balearic Islands, Corsica and North Africa (Table 1). Grouping the two Italian populations did not change the general results, nor did the grouping of North Italy with Monaco (both in Ligurian Sea but quite different on the basis of clustering analysis). For microsatellites, the AMOVA was performed on the basis of allele frequencies $\left(\mathrm{F}_{\mathrm{ST}}\right.$ like) and by taking into account the sum of squared differences of allele sizes $\left(\mathrm{R}_{\mathrm{ST}}\right.$ like). For EF1, the AMOVA was performed without $\left(\mathrm{F}_{\mathrm{ST}}\right.$ like) and with $\left(\Phi_{\mathrm{ST}}\right.$ like) sequence information (proportion of differences). Results were tested with 1,000 permutations.
Isolation by distance

Isolation by distance was tested with microsatellite and EF1 data separately by comparing $\mathrm{F}_{\mathrm{ST}} /\left(1-\mathrm{F}_{\mathrm{ST}}\right)$ with geographical distance (Rousset 1997). Geographical distances were measured on Google Earth as the shortest waterway between populations. IBD web service 3.16 (Jensen et al. 2005) was used to compare non-transformed as well as logarithms of genetic and geographical distances and to test the correlation with a Mantel test applied with 1,000 permutations. A reduced major axis regression was performed.

For all analyses, when necessary, a correction for multiple tests was applied with a false discovery rate of 0.05 (Benjamini and Hochberg 1995).

\section{Results}

Microsatellite polymorphism

Six hundred and ninety-nine individuals corresponding to 24 populations were genotyped with the seven microsatellite loci. The mean number of alleles per loci per population varied from 4.7 (FUE) to 18.7 (FOR) with a mean value of 10.2 (Table S2 supplementary material). The observed heterozygosity varied from 0.39 (TNS) to 0.70 (RIE) with a mean value of 0.56 . Unbiased expected heterozygosity varied from 0.57 (ALB, GHA, TNS) to 0.84 (LPP) with a mean value of 0.71 .The multilocus $\mathrm{F}_{\mathrm{IS}}$ varied from 0.07 (for RIE, Marseilles) to 0.36 (PZU, Corsica) with a mean value of 0.22 . The permutation tests indicated a significant heterozygote deficiency for all populations except for the FUE sample ( $f=0.09 ; P=0.05$ ) (Table S2).

\section{EF1 sequence polymorphism}

In all, $376 \mathrm{EF} 1$ sequences corresponding to 188 individuals were analysed. The length of the sequence alignment was $494 \mathrm{bp}$, with 46 variables sites including four indels of one bp each. The alignment of genomic sequences with the EF1 cDNA sequences of red coral indicated that the length of the intron varied from 344 to $347 \mathrm{bp}$.

Observed heterozygosity varied from 0 (e.g. PZP, Corsica; $n=9$ individuals) to 1 (RIE, Marseilles; $n=8$ ). For the haplotype reconstruction, the five independent runs of the Phase software gave identical results. Most haplotypes were identified with high probability values for the considered sites (0.8-1). Only three different sites in three different individuals had lower probabilities: two at 0.50 and one at 0.56 . The Phase analysis also indicated low recombination rate when considering all sequences with an estimated $\rho$ value of 0.003 , consistent over the five runs. 
Table 2 Sequence polymorphism for the locus EF1 in C. rubrum

\begin{tabular}{|c|c|c|c|c|c|c|c|c|c|c|c|}
\hline Region/population & $\begin{array}{l}\text { Sample } \\
\text { size } \\
\text { (2n genes) }\end{array}$ & $\mathrm{h}$ & $\mathrm{Hd}$ & $\pi$ & $\begin{array}{l}\text { Observed } \\
\text { Fs value }\end{array}$ & $\begin{array}{l}\text { Mean } \\
\text { simulated } \\
\text { Fs }\end{array}$ & $\begin{array}{l}P(\mathrm{Fs} \\
\operatorname{sim} \leq \mathrm{obs})\end{array}$ & $\begin{array}{l}\text { Observed } \\
\text { R2 } \\
\text { statistics }\end{array}$ & $\begin{array}{l}\text { Mean } \\
\text { simulated } \\
\text { R2 }\end{array}$ & $\begin{array}{l}P(\mathrm{R} 2 \\
\operatorname{sim} \leq \mathrm{obs})\end{array}$ & $\begin{array}{l}\text { Tajima's } \\
\text { D }\end{array}$ \\
\hline All & 376 & 39 & 0.88 & 0.006 & -20.95 & -0.55 & 0.00 & 0.03 & 0.07 & 0.04 & -1.73 \\
\hline Adriatic Sea & 42 & 7 & 0.64 & 0.003 & -1.43 & -0.03 & 0.22 & 0.11 & 0.12 & 0.47 & -0.26 \\
\hline North Africa & 64 & 11 & 0.83 & 0.005 & -1.29 & -0.22 & 0.31 & 0.14 & 0.10 & 0.86 & 0.81 \\
\hline Corsica & 48 & 9 & 0.79 & 0.004 & -1.09 & -0.05 & 0.33 & 0.11 & 0.11 & 0.58 & 0.07 \\
\hline South Italy & 14 & 5 & 0.77 & 0.003 & -0.67 & 0.11 & 0.30 & 0.18 & 0.17 & 0.64 & 0.56 \\
\hline North Italy & 14 & 2 & 0.36 & 0.001 & 0.64 & 0.31 & 0.69 & 0.18 & 0.20 & 0.45 & 0.32 \\
\hline Balearic Islands & 24 & 5 & 0.38 & 0.001 & -2.08 & 0.18 & 0.05 & 0.10 & 0.15 & 0.10 & -1.52 \\
\hline Marseilles & 96 & 17 & 0.77 & 0.006 & -2.69 & -0.29 & 0.19 & 0.05 & 0.09 & 0.08 & -1.39 \\
\hline $\begin{array}{l}\text { Villefranche- } \\
\text { Monaco }\end{array}$ & 18 & 4 & 0.66 & 0.002 & 0.18 & 0.08 & 0.57 & 0.14 & 0.16 & 0.35 & -0.05 \\
\hline Catalonia & 56 & 6 & 0.81 & 0.006 & 3.28 & -0.17 & 0.91 & 0.16 & 0.10 & 0.94 & 1.24 \\
\hline \multicolumn{12}{|l|}{ Population } \\
\hline ALB & 28 & 6 & 0.66 & 0.003 & -0.71 & 0.06 & 0.34 & 0.12 & 0.13 & 0.48 & -0.23 \\
\hline GHA & 14 & 3 & 0.62 & 0.002 & 0.78 & 0.23 & 0.69 & 0.24 & 0.18 & 0.81 & 1.46 \\
\hline TEN & 10 & 7 & 0.93 & 0.005 & -2.36 & 0.16 & 0.05 & 0.27 & 0.18 & 0.97 & 2.09 \\
\hline FUE & 36 & 6 & 0.75 & 0.004 & 0.64 & -0.03 & 0.66 & 0.16 & 0.12 & 0.87 & 1.01 \\
\hline DEL & 18 & 4 & 0.73 & 0.006 & 2.78 & 0.05 & 0.91 & 0.21 & 0.14 & 0.96 & 1.40 \\
\hline PZU & 14 & 4 & 0.50 & 0.004 & 1.22 & 0.22 & 0.77 & 0.14 & 0.16 & 0.35 & -0.30 \\
\hline PZP & 18 & 4 & 0.55 & 0.002 & 0.09 & 0.14 & 0.55 & 0.14 & 0.16 & 0.33 & -0.17 \\
\hline APU & 14 & 5 & 0.77 & 0.003 & -0.68 & 0.24 & 0.28 & 0.18 & 0.17 & 0.62 & 0.59 \\
\hline PDA & 14 & 2 & 0.36 & 0.001 & 0.64 & 0.30 & 0.70 & 0.18 & 0.20 & 0.44 & 0.32 \\
\hline LPP & 16 & 3 & 0.24 & 0.001 & -0.98 & 0.25 & 0.10 & 0.13 & 0.19 & 0.21 & -1.04 \\
\hline IML & 10 & 4 & 0.80 & 0.005 & 1.26 & 0.28 & 0.77 & 0.21 & 0.18 & 0.78 & 1.06 \\
\hline RII & 28 & 6 & 0.79 & 0.008 & 2.65 & 0.01 & 0.88 & 0.15 & 0.12 & 0.79 & 0.56 \\
\hline RIE & 16 & 11 & 0.95 & 0.008 & -3.82 & 0.17 & 0.01 & 0.09 & 0.14 & 0.05 & -1.03 \\
\hline MON & 14 & 3 & 0.60 & 0.002 & 0.46 & 0.25 & 0.64 & 0.19 & 0.19 & 0.65 & -0.39 \\
\hline NOR & 16 & 4 & 0.77 & 0.006 & 2.85 & 0.11 & 0.91 & 0.20 & 0.15 & 0.91 & 1.13 \\
\hline POT & 16 & 5 & 0.83 & 0.007 & 1.80 & 0.07 & 0.82 & 0.18 & 0.15 & 0.83 & 0.91 \\
\hline SRE & 10 & 5 & 0.82 & 0.005 & -0.05 & 0.19 & 0.48 & 0.15 & 0.18 & 0.17 & -0.42 \\
\hline
\end{tabular}

The columns indicate the number of analysed sequences for each region or population ( $2 \mathrm{n}$ genes for $\mathrm{n}$ individuals; codes for samples as in Table 1), the number of observed haplotypes (h), the gene diversity (Hd), the nucleotide diversity $(\pi)$, and the results of the analyses of the Fs, R2 and Tajima's $D$ tests. For Fs and R2, the observed value is indicated followed by the mean value obtained over 1,000 coalescent simulations, and the probability that the observed value is higher than the simulated values (see text for details). The first part of the table ("region") gives the results for pooled samples at the regional and global scale; the second part ("population") gives the results at the population level for samples with at least 10 analysed sequences. Values in bold indicate significant tests after correction for multiple test with a false discovery rate of 0.05

For the whole data set, 39 different haplotypes were observed with a nucleotide diversity of 0.006 (Table 2). The most frequent haplotype was found 105 times (frequency 0.28 ) and the second most frequent 49 times (frequency 0.13 ). Eleven haplotypes were observed at least ten times (minimum frequency in the total dataset 0.03 ); most other haplotypes corresponded to one to four occurrences.

At the regional level the number of different haplotypes varied from two (North Italy) to 17 (for Marseilles, the region with the highest sample size; Table 2). Haplotype diversity varied from 0.36 (North Italy) to 0.83 (North Africa). Nucleotide diversity varied from 0.001 (North Italy) to 0.007 (Catalonia and Marseilles; Table 2). At the population level, when considering samples with at least ten sequences, the number of different haplotypes varied from 2 (PDA) to 11 (RIE). Haplotype diversity varied from 0.24 (LPP) to 0.95 (RIE). Nucleotide diversity varied from 0.001 (PDA and LPP) to 0.007 (POT; Table 2).

Tests of mutation-drift equilibrium

\section{Bottleneck tests with microsatellites}

The Wilcoxon's test did not allow detection of any significant heterozygosity excess or deficiency (Table 3). Six tests suggested a significant heterozygosity deficiency at 
Table 3 Tests of mutation-drift equilibrium with microsatellites in C. rubrum: $P$ values for the one-tail Wilcoxon test for heterozygosity excess and deficiency, respectively

\begin{tabular}{lll}
\hline Population & $\begin{array}{l}\text { Heterozygosity } \\
\text { excess }\end{array}$ & $\begin{array}{l}\text { Heterozygosity } \\
\text { deficiency }\end{array}$ \\
\hline ALB & 0.42 & 0.66 \\
GHA & 0.96 & 0.05 \\
TEN & 0.98 & 0.04 \\
TNS & 0.96 & 0.05 \\
FUE & 0.19 & 0.85 \\
DEL & 0.47 & 0.59 \\
BCA & 0.81 & 0.23 \\
PZU & 0.85 & 0.19 \\
POR & 0.96 & 0.05 \\
PDA & 0.85 & 0.19 \\
FOR & 0.85 & 0.19 \\
LPP & 0.96 & 0.05 \\
CRO & 0.97 & 0.04 \\
CAR & 0.96 & 0.05 \\
PON & 0.81 & 0.23 \\
RII & 0.77 & 0.29 \\
RIE & 0.95 & 0.15 \\
TFR & 0.53 & 0.53 \\
MON & 0.85 & 0.19 \\
VIL & 1 & 0.00 \\
NOR & 0.85 & 0.19 \\
CDR & 1 & 0.01 \\
POT & 0.99 & 0.01 \\
SRE & 0.98 & 0.02 \\
\hline NO & & \\
\hline
\end{tabular}

No value was significant after correction for multiple tests with a false discovery rate of 0.05

the 0.05 level, but these tests were not significant after correction for multiple tests.

\section{Selective neutrality tests on EF1}

The results of selective neutrality tests without recombination are presented in Table 2 for samples with at least ten sequences (five individuals) and at global and regional scales (grouped samples). After corrections for multiple tests, only the Fu's Fs test indicated a significant deviation from mutation-drift equilibrium when considering the whole data set, with a highly negative Fs value indicating an excess of rare alleles/rare mutations. The low R2 value $(P=0.04)$ was concordant with this observation. At the regional scale, the signal varied from one region to another and did not evidence any significant or generalised pattern. The analyses of Fu's Fs and R2 with intermediate levels of recombination gave similar results (data not shown). At the population level, only RIE (Marseilles) showed significant
Fs and $\mathrm{R} 2$ values ( $P=0.01$ and 0.05 , respectively) but these values were not significant after correction for multiple tests.

EF1 network reconstruction

The EF1 TCS network is presented in Fig. 2. Most links between haplotypes corresponded to one or two mutations. The highest divergence was observed for four sequences (haplotype XXXVII) from two individuals from RII (Marseilles) which differed by nine mutations from the nearest haplotype (XI). Several loops were present in the network, indicating possible alternative relationships among haplotypes. Several haplotypes (e.g. haplotypes I, III, X, XI) were shared among distant locations, such as the most frequent one $(\mathrm{X})$ which was observed in Marseilles, Monaco, North Italy, Corsica, Catalonia and North Africa. Nevertheless the network showed heterogeneous distribution of the haplotypes.

Clustering analysis

The application of the Structure software to microsatellite data revealed a first peak in the evolution of $\operatorname{Delta}(K)$ at $\mathrm{K}=3$ followed by four smaller peaks at $\mathrm{K}=7,13,21$ and 23 (Fig. S2). The model with independent allele frequencies indicated a first peak at $\mathrm{K}=3$ with a second minor peak at $\mathrm{K}=5$; but for identical $\mathrm{K}$ values the clustering schemes were similar with the two models (data not shown). The solutions with $\mathrm{K}>7$ did not provide much more information than with $\mathrm{K}=7$ and the individual assignment profiles were usually much more complex, therefore, we focused on $\mathrm{K}=3$ and 7 (Fig. 3). For $\mathrm{K}=3$, an African-Adriatic group appeared as separated from a second group with North Italy, Monaco and Marseilles, and a third group with the remaining populations. Apart from the North Italy (PDA) and Balearic samples (FOR, LPP) most samples presented high and homogeneous membership coefficients for their corresponding groups. For $\mathrm{K}=7$, clustering globally followed geographical distribution with more heterogeneous membership coefficients than for $\mathrm{K}=3$. However, Adriatic and African individuals appeared well differentiated from other samples with high membership coefficients. One out of five runs grouped GHA (Adriatic) and CAR (Marseilles). In the four other runs GHA was grouped with the other Adriatic sample (ALB). Corsican and Catalonian samples were also well characterized, apart for SRE (Catalonian) which appeared highly admixed. Samples from Marseilles, Monaco, North Italy and Balearic Islands appeared admixed. Despite this admixture the distribution of the yellow cluster suggested a proximity between samples from Marseilles (except CAR) and those from Monaco. The PDA sample (north Italy) appeared admixed but with a predominance of the Corsican cluster. 
Fig. 2 Statistical parsimony network (TCS) of C. rubrum EF1 haplotypes. Blue Roman numbers correspond to haplotype identifiers. The colors correspond to the regions of origin of the sequences. Pie size indicates the frequency of each haplotype in the total dataset

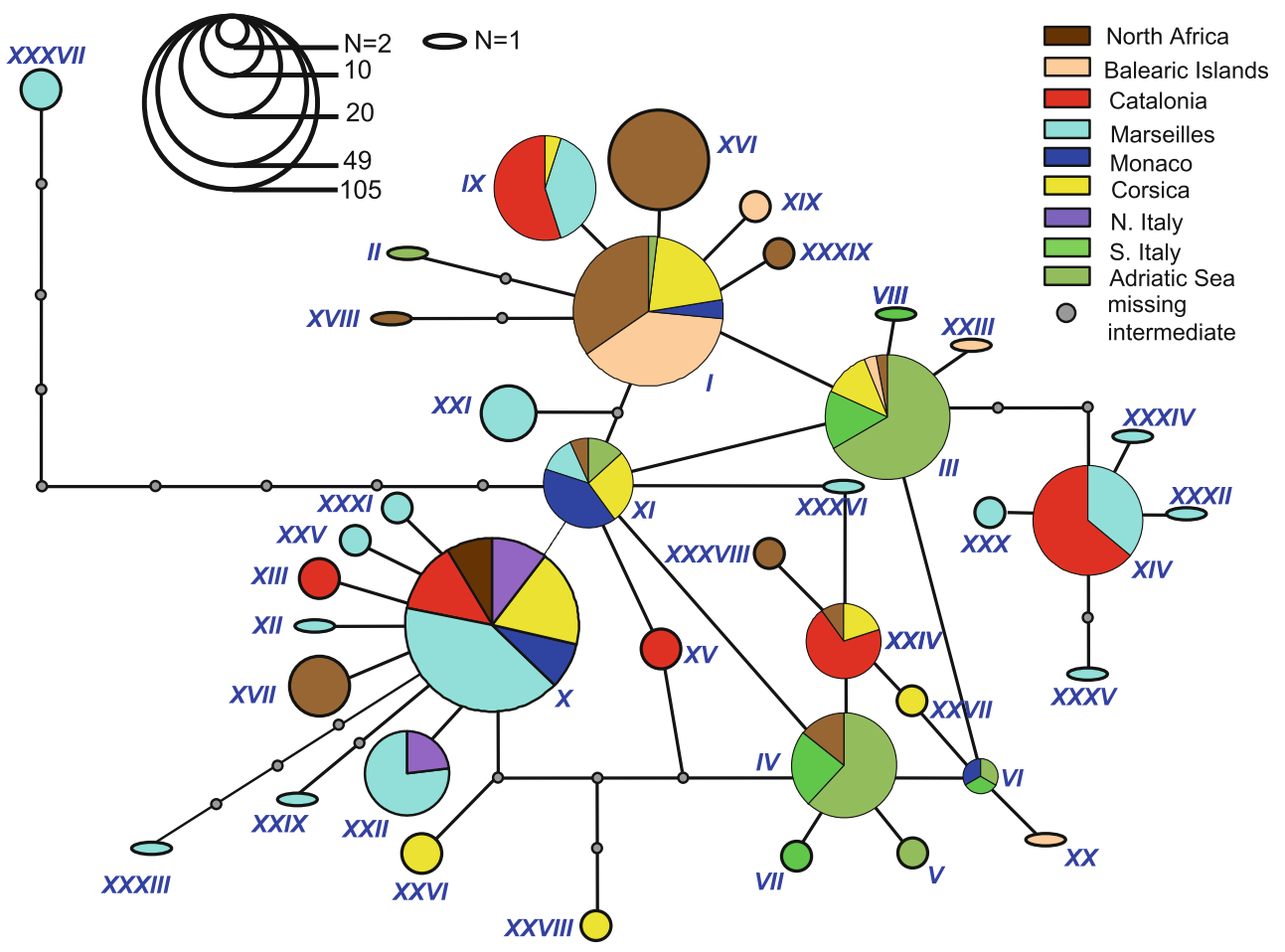

Fig. 3 Results of the structure analysis with microsatellite loci for $\mathrm{K}=3$ and $\mathrm{K}=7$ clusters in C. rubrum. Individuals are represented by vertical bars; the colors correspond to different genetic clusters and the colors proportions of the individuals indicate their membership (from 0 to 1 ) in the corresponding cluster. Each graph corresponds to the combination of five different runs obtained for each $\mathrm{K}$ value. Population codes are indicated in Table 1

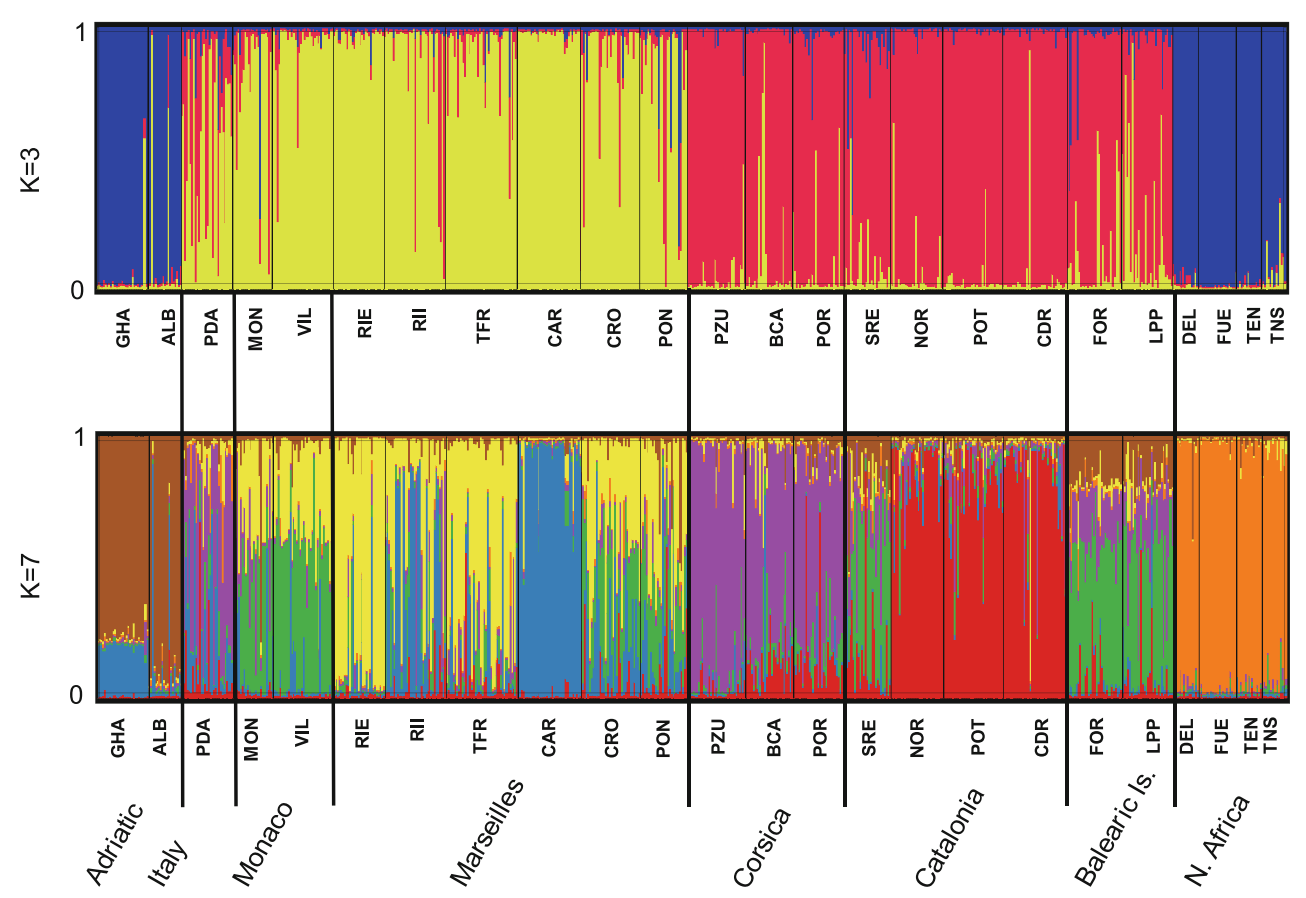

one side and PZU, Corsica on the other side for example; data not shown).

Population differentiation and AMOVA

\section{Genetic differentiation between populations}

For microsatellites, tests of differentiation at the population level indicated significant differentiation for all pairwise 


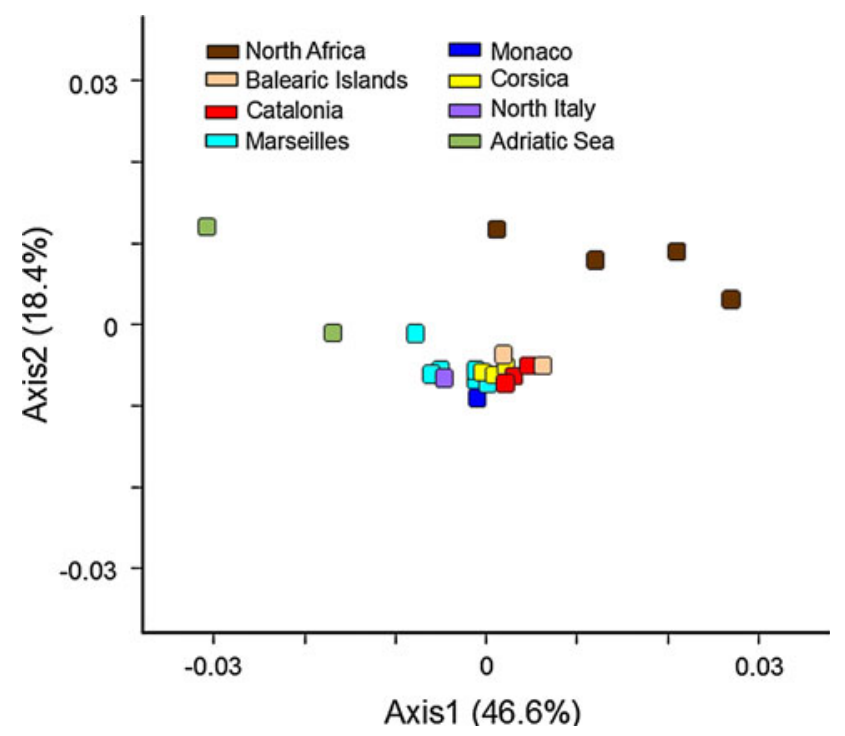

Fig. 4 Principal Coordinates Analysis of the genetic relationships between regions for microsatellite data in C. rubrum. F $_{\mathrm{ST}}$ values were used for population comparison. Percentages of variation explained by the axis: axis 1: $46.6 \%$; axis $2: 18.4 \%$; axis 3 (not shown): $15.4 \%$

comparisons except for the comparisons: RIE-RII, PON-CRO, CDR-POT (Table S3). Highest $\mathrm{F}_{\mathrm{ST}}$ values reached 0.41 and 0.44 for comparisons of GHA (Adriatic) with TEN and TNS (North Africa), respectively. Differentiation tests between regions (as defined in Table 1) were all significant.

For EF1, the estimates $\left(\Phi_{\mathrm{ST}}\right.$ and $\left.\mathrm{F}_{\mathrm{ST}}\right)$ of pairwise population differentiation and results of permutation tests are presented in Tables S4 and S5. The $\Phi_{\mathrm{ST}}$ values varied between -0.75 and 1 , whereas $\mathrm{F}_{\mathrm{ST}}$ varied between -0.3 and 1 . Permutation tests indicated significant differentiation for the comparisons involving the most distant populations such as populations from North Africa or the Balearic Islands compared to those from other regions. When considering all populations, $41 \%$ of the pairwise comparisons were significant with $\mathrm{F}_{\mathrm{ST}}$ and $38 \%$ with $\Phi_{\mathrm{ST}}$. The lowest geographical distance for which significant differentiation was observed with EF1 corresponded to the comparison between RII and RIE: two samples from the same site, but in different environments (inside and outside cave) and about $15 \mathrm{~m}$ apart. For the differentiation test between regions, when using $\Phi_{\mathrm{ST}}$, five tests over $36 \mathrm{com}$ parisons were not significant after correction for multiple tests: Adriatic-South Italy, Marseilles-Catalonia, Marseilles-Monaco, Marseilles-Corsica and Monaco-Corsica. For $\mathrm{F}_{\mathrm{ST}}$ comparisons, seven tests were not significant: Adriatic-South Italy, Monaco-North Italy, MarseillesMonaco, Marseilles-North Italy, Marseilles-Corsica, North Italy-Corsica and Monaco-Corsica.

\section{AMOVA}

For microsatellites, the AMOVA based on $\mathrm{R}_{\mathrm{ST}}$ indicated that around $3 \%$ of the variation corresponded to differences between regions and $18 \%$ to differences between populations within regions (Table 4). With $\mathrm{F}_{\mathrm{ST}}$ like analysis, these percentages were 5 and $8 \%$, respectively. Apart from the comparison between regions with $\mathrm{R}_{\mathrm{ST}}$, permutation tests

Table 4 Results of AMOVA on microsatellites (left) and EF1 sequences (right) in red coral

\begin{tabular}{|c|c|c|c|c|}
\hline \multirow[t]{4}{*}{ Source of variation } & \multicolumn{4}{|l|}{ Marker type } \\
\hline & \multicolumn{2}{|c|}{ Microsatellites } & \multicolumn{2}{|l|}{ EF1 } \\
\hline & $\begin{array}{l}\text { Percentage } \\
\text { of variation }\end{array}$ & Fixation index & $\begin{array}{l}\text { Percentage } \\
\text { of variation }\end{array}$ & Fixation index \\
\hline & & $\mathrm{R}_{\mathrm{ST}}$ like & & $\Phi_{\mathrm{ST}}$ like \\
\hline Among groups & 3.41 & $\mathrm{~F}_{\mathrm{CT}}=0.03(P=0.21)$ & 12.88 & $\mathrm{~F}_{\mathrm{CT}}=0.13(P=0)$ \\
\hline Among populations within groups & 17.13 & $\mathrm{~F}_{\mathrm{SC}}=0.18(P=0)$ & 15.62 & $\mathrm{~F}_{\mathrm{SC}}=0.18(P=0)$ \\
\hline \multirow[t]{2}{*}{ Within populations } & 79.46 & $\mathrm{~F}_{\mathrm{ST}}=0.21(P=0)$ & 71.51 & $\mathrm{~F}_{\mathrm{ST}}=0.28(P=0)$ \\
\hline & & \multicolumn{2}{|l|}{$\mathrm{F}_{\mathrm{ST}}$ like } & $\mathrm{F}_{\mathrm{ST}}$ like \\
\hline Among groups & 4.71 & $\mathrm{~F}_{\mathrm{CT}}=0.05(P=0)$ & 15.04 & $\mathrm{~F}_{\mathrm{CT}}=0.15(P=0)$ \\
\hline $\begin{array}{l}\text { Among populations } \\
\text { within groups }\end{array}$ & 8.34 & $\mathrm{~F}_{\mathrm{SC}}=0.09(P=0)$ & 12.75 & $\mathrm{~F}_{\mathrm{SC}}=0.15(P=0)$ \\
\hline Within populations & 86.94 & $\mathrm{~F}_{\mathrm{ST}}=0.13(P=0)$ & 72.21 & $\mathrm{~F}_{\mathrm{ST}}=0.28(P=0)$ \\
\hline
\end{tabular}


indicated significant differentiation at all levels of analysis. The AMOVA on EF1 sequences performed by taking into account sequence differences $\left(\Phi_{\mathrm{ST}}\right.$-like) indicated that around $13 \%$ of genetic variance was due to differences between regions and $16 \%$ to differences between populations within regions (Table 4). When AMOVA was performed based on haplotype frequencies $\left(\mathrm{F}_{\mathrm{ST}}\right.$-like) these percentages were 15 and $13 \%$, respectively.

\section{Isolation by distance}

The Mantel test applied to microsatellites was significant for all comparisons of genetic and geographical distances either with logarithm or non transformed distances $\left(P<0.001\right.$ in all cases). For the comparison of $\mathrm{F}_{\mathrm{ST}} /\left(1-\mathrm{F}_{\mathrm{ST}}\right)$ with logarithm of geographical distance the reduced major axis regression indicated a positive correlation with $r=0.577$ (estimated slope: 0.127; intercept: -0.173 ). For EF1 data, the Mantel test was significant only when comparing the logarithm of both distances $(P=0.014)$. The reduced major axis regression indicated a positive correlation with $\mathrm{r}=0.133$ (estimated slope: 1.953; intercept: $-5.208)$.

\section{Discussion}

The analysis of genetic differentiation with microsatellite and EF1 suggests a low level of gene flow between red coral shallow-water populations, even at short distance. The genetic structuring of red coral in the north western Mediterranean Sea is congruent with the geographical locations of the populations and led to the identification of three to seven geographical groups. These groups were indeed genetically differentiated which may correspond to barriers to gene flow. Nevertheless the isolation by distance pattern could also explain this geographical structuring. This structuring in geographical groups does not correspond to long-term divergence as suggested by the sharing of EF1 haplotypes between distant locations and by the low level of differences between most haplotypes. The null hypothesis of mutation-drift equilibrium was not rejected. Along with low sequence divergence, this suggests that past environmental fluctuations did not strongly impact the genetic structure and diversity of this species.

Patterns of genetic differentiation

Significant genetic differentiation was evidenced with microsatellites for almost all comparisons between populations and between regions. This agrees with previous studies on red coral using microsatellites (Costantini et al. 2007a, b; Ledoux et al. 2010a). At the population level EF1 data evidenced genetic differentiation at various geographic distances but with a reduced number of significant comparisons when compared with microsatellites. This discrepancy between markers could be linked with differences in sample sizes (lower for EF1). The observation of genetic differentiation starting from short distances is in agreement with the low dispersal abilities of red coral (Costantini et al. 2007a; Ledoux et al. 2010a, b). Nevertheless, the occurrence of individuals with incorrect cluster assignment when considering their geographical origin (Ledoux et al. 2010a; our results) could indicate migration events. Sporadic long distance migration (compared to the mean dispersal distance) might be compatible with genetic differentiation if the level of genetic drift is high enough to overcome gene flow (Tatarenkov et al. 2010). High genetic drift may come from low effective size as is assumed for $C$. rubrum populations (Costantini et al. 2007a; Ledoux et al. 2010b). Sporadic migration may also explain the sharing of EF1 haplotypes among distant locations. A more precise study of migration events should involve individual assignment tests and should be based on a more extensive sampling at regional or local scale.

The spatial pattern of genetic structuring evidenced here extended at higher distances the isolation by distance (IBD) pattern observed by Ledoux et al. (2010a). The Structure and PCA analyses indicated that this genetic structuring agreed well with the geographical location of the populations. Nevertheless, except for North Africa and the Adriatic Sea, individual assignment values obtained with Structure were often low at $K=7$. This could be linked to reduced discriminating power when compared to the results obtained with 10 loci (Ledoux et al. 2010a) or to the effect of unsampled populations, including deep ones. Under isolation by distance (IBD) (as identified in red coral; Ledoux et al. 2010b), the number of clusters inferred by Bayesian structuring can also be overestimated (Frantz et al. 2009), potentially leading to low assignment values (Pritchard et al. 2007). Other factors can potentially bias the clustering approach such as homoplasy with microsatellites at high divergence levels (Viard et al. 1998) or an evolutionary history not compatible with this clustering model (Kalinowski 2011); this could for example explain the grouping of Adriatic and North Africa samples at $\mathrm{K}=3$. The high assignment values observed for North Africa and Adriatic Sea at $\mathrm{K}=7$ seems to correspond to a real distinction of these populations but the analysis of geographically intermediate samples would be necessary to precise this point.

In any case, the differentiation between the geographical groups was significant and the percentage of genetic variation between groups was higher than previously reported (Costantini et al. 2007b; Ledoux et al. 2010a) possibly because of more restricted geographical sampling for these 
previous studies. Higher variation was observed between groups with EF1 than with microsatellites. This may be another consequence of microsatellite allele size homoplasy (Viard et al. 1998) or a consequence of the upper limit of $\mathrm{F}_{\mathrm{ST}}$ estimates inherent to their statistical properties when applied to highly variable markers (Jost 2008). Including EF1 sequence differences in the AMOVA slightly lowered the percentage of variation between groups indicating that this differentiation was not associated with high sequence divergence (see below).

\section{Putative barriers to gene flow}

The genetic structure of red coral agrees well with the gaps in suitable habitats (such as between Marseilles and Catalonia or for insular populations) or with the boundaries between different hydrographic regions as for example between Adriatic and Mediterranean populations. The differentiation of Adriatic populations had been observed for C. rubrum (Costantini et al. 2007b; a single sample) and for other marine organisms (e.g. Ruggiero et al. 2002, for Posidonia oceanica). For C. rubrum, further analyses are required to test whether this differentiation is due to IBD or is reinforced by a barrier to gene flow. Moreover EF1 allele frequencies did not demonstrate significant genetic differentiation between samples from South Italy (APU) and Adriatic Sea; this may be linked to small sample sizes or indicate that the putative barrier between the Adriatic Sea and the rest of the Mediterranean Sea is not located between these locations. In any case the lack of high divergence with EF1 sequences and the geographical distribution of haplotypes did not support the hypothesis of long-term barriers to gene flow (Avise 2000). This is also in agreement with a recent recolonisation of the northern part of the Adriatic Sea following its emersion during glacial events (Ruggiero et al. 2002; Thiede 1978). The presence of a Siculo-Tunisian genetic break (Borsa et al. 1997) also remains to be tested.

Genetic differences were also evidenced between red coral populations from the northern and the southern parts of the western Mediterranean. Nevertheless, as in the case of the Adriatic Sea, there was no deep genetic divergence and the IBD pattern may explain the higher differentiation of the southern samples. South western Mediterranean has been poorly sampled in most phylogeography studies. In the rare cases where the sampling design was suitable, the studied species possessed high dispersal ability and no genetic differentiation was observed (Bahri-Sfar et al. 2000). This north-south differentiation was suspected in Sparus aurata (Chaoui et al. 2009), but the sampling scheme did not allow to precise the origin of this differentiation.
Although the Atlantic-Mediterranean differentiation remains to be investigated more thouroughly in $C$. rubrum, our data provide preliminary information on this point. For various marine organisms the Atlantic-Mediterranean break, when present, is located at the Almeria-Oran front (Borsa et al. 1997; Patarnello et al. 2007 and references therein). The comparison of C. rubrum samples from Ceuta (FUE and DEL) and Algeria (TEN and TNS) located on either side of this front, did not show any particular genetic break with EF1 and these samples were grouped by the clustering analysis (but quite heterogeneous on PCA). This suggests either a more extended influence of Atlantic populations in the Mediterranean, or a lack of such a phylogeographic break for this species. The analysis of Atlantic samples would be necessary to test these hypotheses.

The low divergence among EF1 haplotypes and the sharing of these haplotypes suggest that all the previously discussed barriers did not imply long-term isolation which should have been visible considering the total number of EF1 sequences considered here. This lack of deep divergence may result from a low evolutionary rate for EF1. Though we have no way to estimate the mutation rate for this intron, the observed levels of nucleotide diversity at this locus for $C$. rubrum (0.006) were within the range of values observed in other marine organisms: the deep-water coral Oculina sp. (Eytan et al. 2009) and the deep-sea mussels Bathymodiolus thermophilus and B. azoricus (Faure et al. 2007) for example. This observation does not suggest a particularly low rate of evolution of this marker in red coral. Therefore, a scenario of long-term divergence between regions does not seem probable for red coral. This low divergence also implies that the main genetic groups evidenced here should be considered as management units as suggested in Ledoux et al. (2010a), but not as different evolutionary significant units (sensu Moritz 2002).

\section{Mutation-drift equilibrium}

For EF1, selective neutrality tests (Fs and R2) were significant and suggested a population expansion only when grouping all sequences. These tests were not significant at regional or population scales which may be a consequence of reduced power for these tests with the sample sizes used here (Ramos-Onsins and Rozas 2002). Conversely, the significant signal for the whole dataset could be a false positive signal of expansion induced by grouping genetically differentiated samples (Städler et al. 2009), even if it is not clear whether our sampling scheme and the observed level of differentiation for EF1 could generate this effect. Selection may also produce an apparent expansion signal. This selective hypothesis would require a hitch-hiking effect on a selected locus linked to this intron and a similar scenario has been proposed for EF1 in Mytilus spp. (Faure 
et al. 2008). The demographic hypothesis agrees well with the data of Ledoux et al. (2010a) which evidenced a putative signal of population expansion with microsatellites, but only for 16 out of 40 C. rubrum samples. In our case, the tests applied on microsatellite data were not significant after correction for multiple tests. The analysis of additional nuclear sequence markers and the use of higher sample sizes at population level will be necessary in order to study more precisely the potential departures from mutation-drift equilibrium and to potentially discriminate between the demographic and the selective hypotheses.

\section{Evolutionary history of $C$. rubrum}

The above results on genetic differentiation and selective neutrality tests shed light on the evolutionary history of $C$. rubrum. Two distinct scenarios can be discussed in the context of Quaternary sea-level fluctuations. In the "refugium" scenario, climatic fluctuations would have induced important changes in the distribution area of C. rubrum which could have persisted in geographically distant refugia at the LGM. This should have led to high divergence between source populations and various impacts on genetic diversity including bottlenecks (Hewitt 2000; Petit et al. 2003), but secondary contacts can modify this pattern (Petit et al. 2003). During the last glacial events, the connections between the different basins of the Mediterranean were also potentially more restricted than at present due to sea level variations (Thiede 1978). This could have induced a longterm divergence pattern at least between basins. Alternatively, in the "persistence" scenario, C. rubrum would have persisted in most non-emerged areas with a gradual displacement of populations matching sea level variations. This scenario would have had less marked consequences for genetic structure. The low divergence between populations evidenced in red coral with EF1 sequences and microsatellites offers little support to the refugium scenario but tends to support that of persistence with gradual population displacement. Other observations support the persistence scenario such as the IBD pattern, which could have been broken in case of long distance recolonization (see Castric and Bernatchez 2003). More precise data on selective neutrality tests should help identify potential demographic fluctuations linked with recolonisation.

Therefore, C. rubrum populations may have persisted on the studied geographical area through the last Quaternary fluctuations, potentially with a demographic expansion during the last sea level rise. In a comparative study of 14 rocky-shore species from the northeastern Pacific, Marko et al. (2010) suggested a regional persistence during the LGM: half of these species had histories consistent with long-term stability in population size. A persistence scenario is also coherent with the ecological characteristics of
C. rubrum. In the north western Mediterranean, sea-surface temperatures were lower at the LGM than at present, with estimates of around $7{ }^{\circ} \mathrm{C}$ in winter and $9-13^{\circ} \mathrm{C}$ in summer (Thiede 1978; Hayes et al. 2005). This temperature may have been compatible with the presence of $C$. rubrum in most parts of western Mediterranean Sea as suggested by our results. Few fossil data have been published concerning the genus Corallium, but they suggest that populations of $C$. rubrum have been present without interruption in the Mediterranean basin since the early Pleistocene more than 2,000,000 years ago (Vertino et al. 2010). The study of "deep" samples (i.e. under the depth corresponding to sea level during the LGM) would also be useful to elucidate the evolutionary history of this species, in particular for the identification of putative refugia, either deeper in the same geographical area or in remote areas. Moreover the comparison of the genetic diversity and structure of deep and shallow populations would shed some light on the genetic impact or recolonization processes. Genetic data have been published on deep samples $(600-800 \mathrm{~m})$ revealing differences with shallow populations (Costantini et al. 2010), but the analysis of more individuals, difficult though it be, is required for further interpretation.

Additional nuclear markers will help testing the hypothesis of persistence. Multimarker analyses are required to take into account the inherent variance in genetic and demographic processes. The advances in sequencing technology now allow an easier access to multi-locus data. These data would be useful for a comparative analysis of various evolutionary scenarios. The extension of such studies to other Mediterranean species should help understand the evolutionary history of marine organisms during past environmental fluctuations and to analyse the potential evolution of these organisms in a context of global change.

Acknowledgments We thank Joaquim Garrabou, Olivier Bianchimani, Christian Marschal, Pierre Chevaldonné, Frédéric Zuberer, Roland Graille and Thierry Pérez for providing samples and Didier Forcioli and Helmut Zibrowius for useful comments. We thank Charlotte Roby, Kenza Mokhtar-Jamaï, Emmanuelle Renard, Carole Borchiellini, Emilie Egea, Gwilherm Penant, Eve Gazave and Pascal Lapébie for their help in the laboratory. This work was funded by the French ANR (National Research Agency) in the Medchange program (www.medchange.org). This was also part of the EPIC project in the European Union Network of Excellence Marine Genomics. Some samples were obtained through the GBIRM project in the European Union Network of Excellence MARBEF. J.-B.L's PhD was funded by the Région Provence Alpes Côte d'Azur. Two anonymous reviewers helped us to improve previous versions of this article.

\section{References}

Abbiati M, Santangelo G, Novelli S (1993) Genetic variation within and between two Tyrrhenian populations of the Mediterranean alcyonarian Corallium rubrum. Mar Ecol Prog Ser 95:245-250 
Avise JC (2000) Phylogeography: the history and formation of species. Harvard University Press, Cambridge

Bahri-Sfar L, Lemaire C, Ben Hassine OK, Bonhomme F (2000) Fragmentation of sea bass populations in the western and eastern mediterranean as revealed by microsatellite polymorphism. Proc R Soc Lond B 267:929-935

Belkhir K, Borsa P, Chikhi L, Raufaste N, Bonhomme F (1996-2004) GENETIX 4.05, logiciel sous Windows TM pour la génétique des populations. Laboratoire Génome, Populations, Interactions, CNRS UMR 5000, Université de Montpellier II, Montpellier (France). http://www.genetix.univ-montp2.fr/genetix/genetix.htm

Benjamini Y, Hochberg Y (1995) Controlling the false discovery rate-A practical and powerful approach to multiple testing. J R Statist Soc B 57:289-300

Borsa P, Naciri M, Bahri L, Chikhi L, Garcia de Leon FJ, Kotoulas G, Bonhomme F (1997) Intraspecific zoogeography of the Mediterranean: population genetic analysis on sixteen atlanto-mediterranean species (fish and invertebrates). Vie Milieu 47:295-305

Calderón I, Garrabou J, Aurelle D (2006) Evaluation of the utility of COI and ITS markers as tools for population genetic studies of temperate gorgonians. J Exp Mar Biol Ecol 336:184-197

Castric V, Bernatchez L (2003) The rise and fall of isolation by distance in the anadromous brook charr (Salvelinus fontinalis Mitchill). Genetics 163:966-983

Chaoui L, Hichem Kara M, Quignard J-P, Faure E, Bonhomme F (2009) Forte différenciation génétique de la daurade Sparus aurata (L., 1758) entre les deux rives de la Méditerranée occidentale. C R Biol 332:329-335

Clement M, Posada D, Crandall KA (2000) TCS: a computer program to estimate gene genealogies. Mol Ecol 9:1657-1660

Cornuet JM, Luikart G (1996) Description and power analysis of two tests for detecting recent population bottlenecks from allele frequency data. Genetics 144:2001-2014

Costantini F, Abbiati M (2006) Development of microsatellite markers for the Mediterranean gorgonian coral Corallium rubrum. Mol Ecol Notes 6:521-523

Costantini F, Fauvelot C, Abbiati M (2007a) Fine-scale genetic structuring in Corallium rubrum: evidence of inbreeding and limited effective larval dispersal. Mar Ecol Prog Ser 340: 109-119

Costantini F, Fauvelot C, Abbiati M (2007b) Genetic structuring of the temperate gorgonian coral (Corallium rubrum) across the western Mediterranean Sea revealed by microsatellites and nuclear sequences. Mol Ecol 16:5168-5182

Costantini F, Taviani M, Remia A, Pintus E, Schembri J, Abbiati M (2010) Deep-water Corallium rubrum (L., 1758) from the Mediterranean Sea: preliminary genetic characterisation. Mar Ecol 31:261-269

del Gaudio D, Fortunato G, Borriello M, Gili JM, Buono P, Calcagno G, Salvatore F, Sacchetti L (2005) Genetic typing of Corallium rubrum. Mar Biotech 6:511-515

Duran S, Giribet G, Turon X (2004) Phylogeographical history of the sponge Crambe crambe (porifera, poecilosclerida): range expansion and recent invasion of the Macaronesian islands from the Mediterranean Sea. Mol Ecol 13:109-122

Evanno G, Regnaut S, Goudet J (2005) Detecting the number of clusters of individuals using the software STRUCTURE: a simulation study. Mol Ecol 14:2611-2620

Excoffier L, Smouse PE, Quattro JM (1992) Analysis of molecular variance inferred from metric distances among DNA haplotypes: application to human mitochondrial DNA restriction data. Genetics 131:479-491

Excoffier L, Laval G, Schneider S (2005) Arlequin (version 3.0): an integrated software package for population genetics data analysis. Evol Bioinform Online 1:47-50
Eytan R, Hayes M, Arbour-Reily P, Miller M, Hellberg M (2009) Nuclear sequences reveal mid-range isolation of an imperilled deep-water coral population. Mol Ecol 18:2375-2389

Falush D, Stephens M, Pritchard JK (2003) Inference of population structure using multilocus genotype data: linked loci and correlated allele frequencies. Genetics 164:1567-1587

Faure B, Bierne N, Tanguy A, Bonhomme F, Jollivet D (2007) Evidence for a slightly deleterious effect of intron polymorphisms at the EF1 $\alpha$ gene in the deep-sea hydrothermal vent bivalve bathymodiolus. Gene 406:99-107

Faure M, David P, Bonhomme F, Bierne N (2008) Genetic hitchhiking in a subdivided population of Mytilus edulis. BMC Evol Biol 8:164

Féral JP (2002) How useful are the genetic markers in attempts to understand and manage biodiversity? J Exp Mar Biol Ecol 268:121-145

Frantz A, Cellina S, Krier A, Schley L, Burke T (2009) Using spatial bayesian methods to determine the genetic structure of a continuously distributed population: clusters or isolation by distance? J Appl Ecol 46:493-505

Fu YX (1997) Statistical tests of neutrality of mutations against population growth, hitchhiking and background selection. Genetics 147:915-925

Garrabou J, Harmelin JG (2002) A 20-year study on life-history traits of a harvested long-lived temperate coral in the NW Mediterranean: insights into conservation and management needs. J Anim Ecol 71:966-978

Garrabou J, Coma R, Bensoussan N, Chevaldonné P, Cigliano M et al (2009) Mass mortality in NW Mediterranean rocky benthic communities: effects of the 2003 heat wave. Glob Change Biol 15:1090-1103

Hall TA (1999) BioEdit: a user-friendly biological sequence alignment editor and analysis program for Windows 95/98/NT. Nucl Acids Symp Ser 41:95-98

Hayes A, Kucera M, Kallel N, Sbaffi L, Rohling EJ (2005) Glacial mediterranean sea surface temperatures based on planktonic foraminiferal assemblages. Quat Sci Rev 24:999-1016

Hewitt G (2000) The genetic legacy of the quaternary ice ages. Nature 405:907-913

Jensen J, Bohonak A, Kelley S (2005) Isolation by distance, web service. BMC Genet 6:1-6

Jost L (2008) $\mathrm{G}_{\mathrm{ST}}$ and its relatives do not measure differentiation. Mol Ecol 17:4015-4026

Kalinowski ST (2011) The computer program STRUCTURE does not reliably identify the main genetic clusters within species: simulations and implications for human population structure. Heredity 106:625-632

Lambeck K, Bard E (2000) Sea-level change along the French Mediterranean coast for the past 30000 years. Earth Planet Sci Lett 175:203-222

Ledoux JB, Mokthar-Jamaï K, Roby C, Féral JP, Garrabou J, Aurelle D (2010a) Genetic survey of shallow populations of the Mediterranean red coral (Corallium rubrum (Linnaeus, 1758)): new insights into evolutionary processes shaping nuclear diversity and implications for conservation. Mol Ecol 19:675-690

Ledoux JB, Garrabou J, Bianchimani O, Drap P, Féral JP, Aurelle D (2010b) Fine-scale genetic structure and inferences on population biology in the threatened Mediterranean red coral, Corallium rubrum. Mol Ecol 19:4204-4216

Li N, Stephens M (2003) Modelling linkage disequilibrium and identifying recombination hotspots using single-nucleotide polymorphism data. Genetics 165:2213-2233

Librado P, Rozas J (2009) DnaSP v5: a software for comprehensive analysis of DNA polymorphism data. Bioinformatics 25: $1451-1452$ 
Maggs CA, Castilho R, Foltz D, Henzler C, Taimour Jolly M, Kelly J, Olsen J, Perez KE, Stam W, Väinölä R, Viard F, Wares J (2008) Evalutating signatures of glacial refugia for north atlantic benthic marine taxa. Ecology 89:S108-S122

Marko P, Hoffman J, Emme S, McGovern T, Keever C, Cox L (2010) The "expansion-contraction" model of pleistocene biogeography: rocky shores suffer a sea change? Mol Ecol 19:146-169

Moritz C (2002) Strategies to protect biological diversity and the evolutionary processes that sustain it. Syst Biol 51:238-254

Nei M (1987) Molecular evolutionary genetics. Columbia University Press, New York

Orloci L (1978) Multivariate analysis in vegetation research. Dr W Junk BV, The Hague

Patarnello T, Volckaert FAMJ, Castilho R (2007) Pillars of Hercules: is the Atlantic-Mediterranean transition a phylogeographical break? Mol Ecol 16:4426-4444

Peakall R, Smouse PE (2006) GENALEX 6: genetic analysis in Excel. Population genetic software for teaching and research. Mol Ecol Notes 6:288-295

Petit RJ, Aguinagalde I, de Beaulieu J, Bittkau C, Brewer S, Cheddadi $R$ et al (2003) Glacial refugia: hotspots but not melting pots of genetic diversity. Science 300:15S63-15S1565

Piry S, Luikart G, Cornuet JM (1999) BOTTLENECK: a computer program for detecting recent reductions in the effective population size using allele frequency data. J Hered 90(4):502-503

Pritchard JK, Stephens M, Donnelly P (2000) Inference of population structure using multilocus genotype data. Genetics 155:945-959

Pritchard J, Wen X, Falush D (2007) Documentation for structure software: version 2.2

Ramírez-Soriano A, Ramos-Onsins SE, Rozas J, Calafell F, Navarro A (2008) Statistical power analysis of neutrality tests under demographic expansions, contractions and bottlenecks with recombination. Genetics 179:555-567

Ramos-Onsins SE, Rozas J (2002) Statistical properties of new neutrality tests against population growth. Mol Biol Evol 19: 2092-2100

Rousset F (1997) Genetic differentiation and estimation of gene flow from F-statistics under isolation by distance. Genetics 145: 1219-1228

Rozen S, Skaletsky HJ (2000) Primer3 on the WWW for general users and for biologist programmers. In: Krawetz S, Misener S (eds) Bioinformatics methods and protocols: methods in molecular biology. Humana Press, Totowa, pp 365-386

Ruggiero M, Turk R, Procaccini G (2002) Genetic identity and homozygosity in north-adriatic populations of Posidonia oceanica: an ancient, post-glacial clone? Cons Gen 3:71-74
Santangelo G, Bramanti L, Iannelli M (2007) Population dynamics and conservation biology of the over-exploited Mediterranean red coral. J Theo Biol 244:416-423

Serra IA, Innocenti AM, Di Maida G, Calvo S, Migliaccio M, Zambianchi E et al (2010) Genetic structure in the Mediterranean seagrass Posidonia oceanica: disentangling past vicariance events from contemporary patterns of gene flow. Mol Ecol 19:557-568

Städler T, Haubold B, Merino C, Stephan W, Pfaffelhuber P (2009) The impact of sampling schemes on the site frequency spectrum in nonequilibrium subdivided populations. Genetics 182:205-216

Stephens M, Scheet P (2005) Accounting for decay of linkage disequilibrium in haplotype inference and missing data imputation. Am J Hum Gen 76:449-462

Stephens M, Smith NJ, Donnelly P (2001) A new statistical method for haplotype reconstruction from population data. Am J Hum Gen 68:978-989

Tajima F (1989) Statistical method for testing the neutral mutation hypothesis by DNA polymorphism. Genetics 123:585-595

Tatarenkov A, Healey CIM, Avise JC (2010) Microgeographic population structure of green swordail fish: genetic differentiation despite abundant migration. Mol Ecol 19:257-268

Thiede J (1978) A glacial Mediterranean. Nature 276:680-683

Vertino A, Zibrowius H, Taviani M (2010) Fossil ancestors of family Coralliidae in the Mediterranean Sea. In: Bussoletti E, Cottingham D, Bruckner A, Roberts G and Sandulli R (eds) Proceedings of the international workshop on red coral science, management, and trade: lessons from the Mediterranean. NOAA Technical Memorandum CRCP-13, Silver Spring, MD, pp 94-98

Viard F, Franck P, Dubois M, Estoup A, Jarne P (1998) Variation of microsatellite size homoplasy across electromorphs, loci, and populations in three invertebrate species. J Mol Evol 47:42-51

Vighi M (1972) Etude sur la reproduction du Corallium rubrum (L.). Vie et milieu 23:21-32

Weinberg S (1979) The light-dependent behaviour of planula larvae of Eunicella singularis and Corallium rubrum and its implication for octocorallian ecology. Bijdragen tot de Dierkunde 49:16-30

Weir B, Cockerham C (1984) Estimating F-statistics for the analysis of population structure. Evolution 38:1358-1370

Zibrowius H, Monteiro Marques V, Grasshoff M (1984) La répartition du Corallium rubrum dans l'Atlantique (Cnidaria: Anthozoa: Gorgonaria). Téthys 11:163-170 